\title{
Grassy Odour in Beef
}

\author{
Jana Fořtová Ing ${ }^{1,2}$ and Mgr Petr Doležal PhD ${ }^{2}$ \\ ${ }^{1}$ Department of Cattle Breeding, Institute of Animal Science, Uhřiněves 104 00, Prague 10, Czech Republic \\ ${ }^{2}$ Department of Quality of Agricultural Products, Faculty of Agrobiology, Food and Natural Resources, Czech University of Life \\ Sciences, Prague 165 21, Czech Republic
}

*Corresponding author: Jana Fořtová Ing, Department of Cattle Breeding, Institute of Animal Science, Uhříněves 10400 , Prague 10, Czech Republic

\begin{tabular}{|c|c|}
\hline ARTICLE INFO & ABSTRACT \\
\hline Received: 慧 September 23, 2019 & There were used 6 bulls fed by corn silage $(42,4 \%)$, lucerne silage $(40,2)$, corn grain \\
\hline Published: 慧October 01, 2019 & $\begin{array}{l}\text { moistened }(10,3) \text {, wheat grain }(5,8) \text {, and mineral mix with urea }(1,1 \%) \text { to characterize } \\
\text { the odour quality by olfactometry. Every beef sample was assessed by } 6 \text { evaluators. }\end{array}$ \\
\hline $\begin{array}{l}\text { Citation: Jana Fořtová Ing, Mgr Petr } \\
\text { Doležal PhD. Grassy Odour in Beef. } \\
\text { Biomed J Sci \& Tech Res 21(4)-2019. } \\
\text { BJSTR. MS.ID.003643. }\end{array}$ & $\begin{array}{l}\text { Although meat odour is logically the most expected, the grassy odour was the most } \\
\text { presented odour and mostly identified as hexanal. Hexanal was presented in every } \\
\text { sample and it was identified certainty and it was always described as grassy. Hexanal is } \\
\text { commonly found in beef, it is a product of oxidation of oleic and linoleic acids. Because } \\
\text { of it some researchers identified it as the unpleasant compound but others as a pleasant } \\
\text { compound as we did. However hexanal is presented as in the grain-fed so in the forage- }\end{array}$ \\
\hline $\begin{array}{l}\text { Abbreviations: PDMS: Polydimethylsilo- } \\
\text { xane; DVB: Divinylbenzene; FID: Flame }\end{array}$ & $\begin{array}{l}\text { fed ruminant meat in literature. It remains the question of hexanal influence on beef } \\
\text { palatability. }\end{array}$ \\
\hline
\end{tabular}

Keyword: Beef Quality; Hexanal; Grassy Odour; Oxidation

\section{Short Communication}

The quality of beef is given by a number of factors whereas the most important are considered the texture properties and the odour [1]. Heat treatment of meat at a minimum of $192{ }^{\circ} \mathrm{C}$ produces oxidation products such as hexanal [2]. Hexanal is the compound producing grassy odour [3]. To analyze the odour, there were used olfactometry as the widely used method in this field nowadays [4]. Olfactometry is a method that gives a description of the separated compounds assessed by assessors. It was analyzed the Fleckvieh cattle which is a local breed in the Czech Republic whose history dates back to the second half of the 19th century. Czech consumers traditionally prefer young bulls, thus male individuals slaughtered from 12 to 24 months of age. For our purposes was used longissimus lumborum muscle which is the main part of the loin and its activity is related to the movements of the spine. This muscle is one of the largest in the carcass; it has quite homogeneous structure and it is often used as a reference muscle in the evaluation of meat quality.

Also, it is widely consumed grilled for its high score of tenderness and also for its pleasant odour. It is supposed that the fatty acids of the feeding are deposited in the meat [5]. In the case of corn feeding, heifers supplemented with corn oil tended to have higher marbling scores following 32 days of treatment than those supplemented with rumen protected conjugated linoleic acid, with controls intermediate [6]. There are also differences into the foragefed and grain-fed cattle. Meat of forage-fed ruminants contained more linolenic and additional n-3 polyunsaturated fatty acids, while meat from grain-fed ruminants contains more oleic, linoleic acid, and other n-6 polyunsaturated fatty acids [7]. It is supposed, that forage-fed ruminants tend to have higher score of grassy odour assessed by sensory panelists [8]. But some researchers claim that is not so obvious [9].

\section{Material and Methods}

There were selected 6 young bulls from the experimental unit of the Institute of Animal Science. Bulls were fed by corn silage $(42,4 \%)$, lucerne silage $(40,2)$, corn grain moistened $(10,3)$, wheat grain $(5,8)$, and mineral mix with urea $(1,1 \%)$. There was taken longissimus lumborum from everyone for the analysis. The samples were aged for 15 days and frozen at $-20{ }^{\circ} \mathrm{C}$ until unfrozen them before the day of analysis. Before its own analysis 6 assessors were selected and trained. Testing first samples we noticed hexanal as the most important compound. To determine assessor's perception defect was used the triangular test. We decided to be realized it with hexanal using recommended concentration threshold of 5.87 
ppm [10]. We did a dilution test to determine the threshold but also possibly changes in odour perception which were not detected. Than the assessors were trained using five steps: introduction of GC-0 methods to the panelists during 2 days of theory lectures; vocabulary training using standard compounds; training with reference mixture; sniffing the product of interest; monitoring and further training of the panel twice per month using reference mixture.

The vocabulary was set according to literature as odours that may appear in a beef sample and using examples [11]. The sample were grilled at $200^{\circ} \mathrm{C}$ to get $70{ }^{\circ} \mathrm{C}$ of internal temperature of meat measured by thermometer, homogenized, weighed 2 grams of it and added $4 \mathrm{ml}$ of mili $\mathrm{Q}$ watter into to $10 \mathrm{ml}$ vial to simulate the eating process. There were preparated 6 samples of one meat to every assessor. There were used SMPE sorption on polydimethylsiloxane/ divinylbenzene (PDMS/DVB) pink fiber of $65 \mu \mathrm{m}$ film thickness from Supelco (Madrid, Spain). The sample were sorbed 40 minutes and then placed into gas gromatograph to analyze. To determine the linear retention index, the C7-C40 saturated alkane mix (Supelco) was used. Ultrapure water (generated using Aqual ${ }^{\circledR}$ 35, Aqual, Brno, Czech Republic) was utilized for extraction. For qualitative and quantitative analyses, multidimensional gas chromatography coupled to a flame ionization detector and a mass spectrometry detector (MDGC/FID/MS) was used. The MDGC/FID/ MS system was also equipped with GC-2010 and the autosampler AOC20i (Shimadzu, Kyoto, Japan). The first dimension of the chromatographic system was the GC-FID system.

A fused-silica capillary SLB-5ms column (30 m, i.d. $0.32 \mathrm{~mm}$ $1.0 \mu \mathrm{m}$ d.f., Supelco, USA) was used for the separation. The samples $(1 \mu \mathrm{L})$ were injected in the inlet in the split less mode and were heated at $250{ }^{\circ} \mathrm{C}$. He (purity 5.0) was used as the carrier gas with a linear velocity of $1.14 \mathrm{~mL} / \mathrm{min}(115.9 \mathrm{kPa})$. The flame ionization detector (FID) was heated at $260{ }^{\circ} \mathrm{C}$. The temperature program for the first dimension (GC1) started at $120^{\circ} \mathrm{C}(0 \mathrm{~min})$, and then, the temperature was increased to $250{ }^{\circ} \mathrm{C}$ at a heating rate of 15 ${ }^{\circ} \mathrm{C} / \mathrm{min}$, after which this temperature was held for $5.88 \mathrm{~min}$. The second column (GC2) was SPB-50 (30 m, i.d. $0.35 \mathrm{~mm}, 0.25 \mu \mathrm{m}$ d.f., Sigma-Aldrichl, Merck, Germany). In GC2, the same temperature program as that in GC1 was used. The total run time was $14,55 \mathrm{~min}$. A mass detector (GCMS-QP2010 Ultra, Shimadzu, Kyoto, Japan) was connected after this second column. Selected peaks were switched to the second dimension via the Deans switching device (SHIMADZU 221-71468-91 Switching Assy, Shimadzu, Kyoto, Japan) with 100\% switching recovery and a switching pressure of $50 \mathrm{kPa}$.

During the analysis, the whole MDGC-MS system was controlled using the software MDGC Solution 1.01.00, a GC Solution 240.00 from the same company. The qualitative analysis was carried out using the mass detector (MS). A transfer-line in the MS was heated at $260{ }^{\circ} \mathrm{C}$ and the ion source temperature was set to $220{ }^{\circ} \mathrm{C}$. For the qualitative analysis, the MS detector operated in the electron ionization (EI) mode at $-70 \mathrm{eV}$ : a mass range of 30-300 amu was obtained, with an acquisition rate of $10 \mathrm{~Hz}$. For quantification there were used isothermal desorption hold on $200^{\circ} \mathrm{C}$ during 43 min using 2,6-dichloroanisole ( $\geq 99 \%$, Sigma-Aldrich, Merck, USA); Butanoic acid, 2- methyl- , methyl ester (99\%, Sigma-Aldrich, Merck, USA) as internal standards and 44,56 and 41 fragment peak to determine the peak area. To determine the statistical difference, there were used GLM procedure and MIXED procedure with the day as random effect included. The data presented in the tables are expressed as the smallest average squares (LSM) with its standard error (SEM).

\section{Results}

There were realized the fatty acid composition of the feeding components with a noticeable fat content to justify the fatty acids oxidation as the cause of the aldehydes release. The fatty acid composition is mentioned in the Table 1. Other fatty acids were presented in smaller content than $1 \mathrm{mg} / \mathrm{kg}$ of meat. Thus, a noticeable hexanal content was assumed and grassy odour was expected (Table 1). In the part of olfactometry, there were obtained three types of results: description of separated compounds, peak area of all compounds desorbed and quantification also. The most frequent description of the volatile compound was the stale (wet or moldy cellar/textile; moldy or spoiled food) and lemon or sour and some unidentified unpleasant smell probably incurred during the sample storage followed by the sum of fruit mostly non recognized type (banana, plum, berries, apricot, fermented fruit) followed by well recognized grassy odour. The frequency of odour described is mentioned in the Figure 1 . In the Figure 2 we can see the calculated peak area of all compounds analysed together. We can notice an importance of hexanal area. In the Table 1 there are the significant data about quantification of grassy odour. There were determinate 15 compounds of grassy odour. The largest peak area was determinate as the hexanal peak area (Figures 1 \& 2) (Table 2).

Table 1: The most important fatty acid of the feeding components.

\begin{tabular}{|c|c|c|}
\hline Fatty Acids Composition [mg/kg of meat] & Wheat Grain & Corn Grain Moistened \\
\hline Linoleic acid & 53,015 & 27,083 \\
\hline Oleic acid C 18:1-n9 & 15,065 & 2,318 \\
\hline Oleic acid C 18:1-n7 & $16,344,380$ \\
\hline Palmitic acid & 4,477 & 1,424 \\
\hline S- Linolenoic acid & 1,174 & 1,990 \\
\hline
\end{tabular}


Table 2: Compounds of grassy odour [method used for calculation: LSM].

\begin{tabular}{|c|c|c|c|c|c|}
\hline & Retention time & Retention index & Estimate & SE & P-value \\
\hline Compound 1 & 15.108 & 737 & & & \\
\hline Pyridine & 15.572 & 750 & 36155 & 17189 & 0.0516 \\
\hline Compound 3 & 16.201 & 771 & & & \\
\hline Hexanal & 17.23 & 804 & 455706 & 103563 & 0.0004 \\
\hline Compound 5 & 20.092 & 905 & & & \\
\hline Compound 6 & 22.311 & 999 & & & \\
\hline Nonanal & 24.314 & 1089 & 132253 & 17140 & $<.0001$ \\
\hline Compound 8 & 25.002 & 1121 & & & \\
\hline Compound 9 & 26.071 & 1170 & & & \\
\hline Dodecane & 26.188 & 1175 & 3979.58 & 861.76 & 0.0003 \\
\hline Compound 11 & 26.321 & 1185 & & & \\
\hline Compound 12 & $27 . \mathrm{V}$ & 1248 & & & \\
\hline Decanoic acid & 28.802 & 1316 & 6037.41 & 2264.40 & 0.0169 \\
\hline Compound 14 & 29.453 & 1349 & & & \\
\hline Compound 15 & 31.02 & 1437 & & & \\
\hline
\end{tabular}

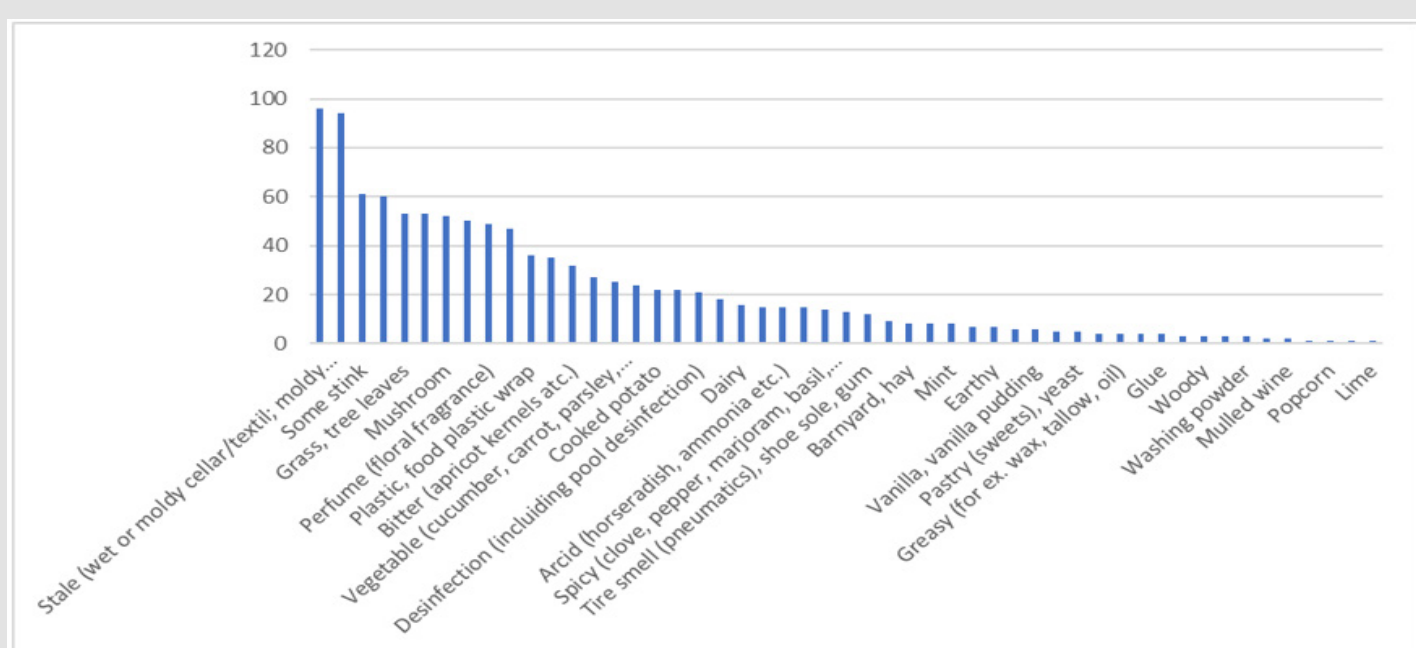

Figure 1: Frequency of odours [number of evaluations].

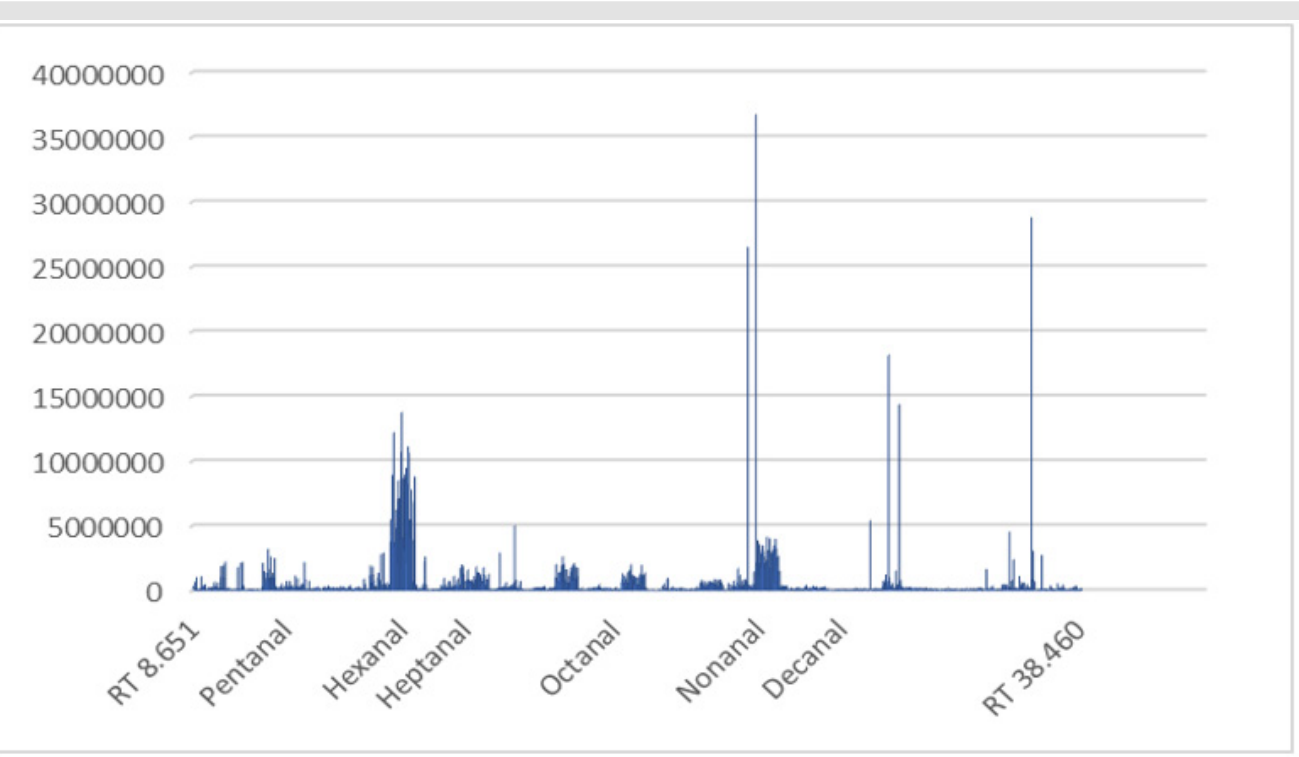

Figure 2: Peak area of the compounds [intensity due to the base peak]. 


\section{Discussion}

The grassy odour is an important odour of beef. There were analyzed hexanal as the most important compound of the grassy odour. The hexanal content should be related to the oxidation of oleic and linoleic acid [12]. It was determined the highest content of these acids in the fat of animal feeding, so it was expected certain content of hexanal. It is assumed that the lipid oxidation of meat is unpleasant and arises off-flavours [10]. But the grassy odour of hexanal was pleasant for the assessors. Also, it's a compound commonly found in beef and its content is expected even in the most favorite beef breeds. For example, there were set an experiment realized with Angus breed finished on a mixed ration including wheat and potato waste for 150 days, grass-fed Angus and grassfed Waggyu breed. These two breeds are known to have the highest content of intramuscular fat so its pretended that the content of oleic and linoleic acid is also high and subsequently causes the increased content of hexanal. In all of three cases the hexanal had the third highest content of all the volatiles determinate, $33,4 \mathrm{mg} /$ $\mathrm{kg}$ of meat, $17,7 \mathrm{mg} / \mathrm{kg}$ of meat and $33,5 \mathrm{mg} / \mathrm{kg}$ of meat [9].

\section{Conclusion}

As the conclusion, grassy odour is an important meat odour. It may provide from hexanal which is damned by some researchers as the undesirable product of oxidation, but assessors assessed it as pleasant grassy odour. It was the most intensive compound recognized and it had significative representation in the meat.

\section{References}

1. Hocquette J F, Van Wezelmael L, Chriki S, Legrand I, Verbeke W, et al. (2014) Modelling of beef sensory quality for a better prediction of palatability. Meat Sci 97(3): 316-322.

\section{ISSN: 2574-1241}

DOI: $10.26717 /$ BJSTR.2019.21.003643

Jana Fořtová. Biomed J Sci \& Tech Res

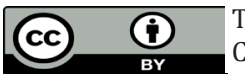

This work is licensed under Creative Commons Attribution 4.0 License

Submission Link: https://biomedres.us/submit-manuscript.php
2. Whitfield FB (1992) Volatiles from interactions of Maillard reactions and lipids. Critical Reviews in Food Science and Nutrition 31(1-2): 1-58.

3. Mottram DS (1998) Flavour formation in meat and meat products: A review. Food Chemistry 62(4): 415-424.

4. Delahunty CM1, Eyres G, Dufour JP (2006) Review Gas chromatographyolfactometry. J Sep Sci 29(14): 2107-2125.

5. Khanal R, Olson K (2004) Factors affecting conjugated linoleic acid (CLA) content in milk, meat, and egg: a review. Pak J Nutr 3(2): 82-98.

6. Duckett, SK, Realini CE, Keisler D, Pringle D, Gillis MH, et al. (2004) Effects of supplemental rumen-protected conjugated linoleic acid or linoleic acid on feedlot performance , carcass quality , and leptin concentrations in beef cattle. Journal of Animal Science 82(3): 851-859.

7. Calkins CR, Hodgen J (2007) A fresh look at meat flavor. Meat Sci 77(1): 63-80.

8. Larick D, Turner B (1990) Headspace volatiles and sensory characteristics of ground beef from forage-and grain-fed heifers. J Food Sci 55(3): 649-654.

9. Frank D, Ball A, Hughes J, Krishnamurthy R, Piyasiri U, et al. (2016) Sensory and Flavor Chemistry Characteristics of Australian Beef; the Influence of Intramuscular Fat, Feed and Breed. Journal of agricultural and food chemistry 64(21): 4299-4311.

10. Brewer MS, Vega JD (1995) Detectable odor thresholds of selected lipid oxidation compounds in a meat model system. Journal of Food Science 60(3): 592-595.

11. Vene K, Leitner E, K Koppel, T Paalme (2013) A Method for GC Olfactometry Panel Training. Chem. Percept 6(4): 179-189.

12. Xu L, Yu X, Li M, Chen J, Wang X (2018) Monitoring oxidative stability and changes in key volatile compounds in edible oils during ambient storage through HS-SPME / GC - MS. International Journal of Food Properties 20(3): 2926-2938.

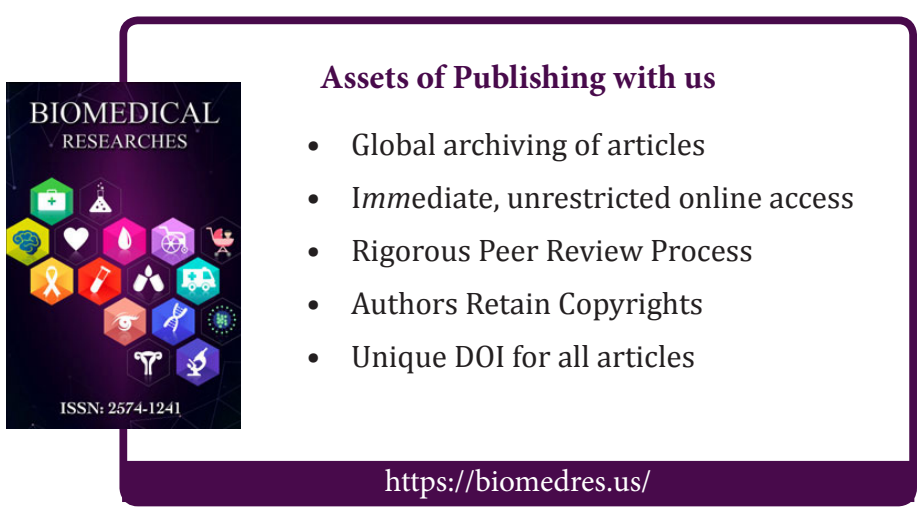

